\title{
Modelling Mortality Using Life Trajectories of Disabled and Non-Disabled Individuals in Nineteenth-Century Sweden
}

\author{
Erling Häggström Lundevaller, Lotta Vikström, and Helena Haage
}

\section{Introduction}

The purpose of this study is to investigate how disabilities and the experiences of work and family during early adulthood affected subsequent mortality in past society. As in many other historical demographic studies, this calls for a life course approach and a choice of analysis methods accordingly.

In the last two decades, statistician Gilbert Ritschard has promoted sequence analysis for studying events during extended time spans of individual life, just as the research of he and his colleagues has shown (Oris and Ritschard 2014; Ritschard and Oris 2005; Ritschard et al. 2008; Studer and Ritschard 2016). Although statistical life course analysis has come to predominate within the field of historical demography when there is ample access to data, the method of sequence analysis has been of limited use compared to Cox regression models. While the latter models provide accurate estimates of significant factors determining the single event under study, sequence analysis examines a series of several events that help to grasp the life course as the dynamic process it is.

Researchers increasingly call for a combination of the two methods that can work to complement each other (Courgeau 2018; Kok 2007; Madero-Cabib et al. 2015) and some of them have undertaken such an approach of interest to historical demography (Bras et al. 2010; Dribe et al. 2014; Schumacher et al. 2013). A similar approach, but with logistic regression in place of Cox regression, is proposed in Rossignon et al. (2018). See also the first case study in Eerola (2018). We appreciate this move towards joining methods and the present study is an attempt to test this combination so as to contribute results that reflect life and death among disabled

\footnotetext{
E. H. Lundevaller $(\bowtie) \cdot$ L. Vikström $\cdot$ H. Haage

Umeå University, Umeå, Sweden

e-mail: erling.lundevaller@umu.se

(C) The Author(s) 2018

G. Ritschard, M. Studer (eds.), Sequence Analysis and Related Approaches, 
people historically. They constitute a group whose demographic experiences have received poor recognition in historical research and who are rarely subject to the statistical use of life course analyses.

Our study aims to detect the life sequences among young adults pertaining to their transition to work and family formation, and then see whether there are significant associations between the mortality risks and the specific life sequences we find in a nineteenth-century Swedish population comprising both disabled and non-disabled men and women.

Our previous findings are primarily based on Cox regression models using a larger population (some 35,000 cases), a selection of which is targeted below ( $N=4,116)$, that originate from Swedish parish registers digitised by the Demographic Data Base (DDB), Umeå University. Our mortality results demonstrate that disabilities caused people to have significantly higher premature death propensity ( $<54$ years of age), in particular if having mental disorders or if male regardless of type of disability (Haage et al. 2016). In another study, our Cox regression results suggest that disability jeopardised the marital propensity in similar ways (Haage et al. 2017). In a recent study, we employ sequence analysis on a series of events expected to occur in the life of young adults: work, marriage and parenthood, also taking some account of outward migration and death (Vikström et al. 2017). We found that the trajectories of disabled individuals did not include work or family to the same extent as those of non-disabled people, and that they rarely migrated, but suffered from premature death $(<34$ years of age). The trajectory findings from conducting sequence analysis and the mortality results obtained through Cox regressions models made us curious about the outcomes from combining the two methods somehow, as increasingly suggested by life course scholars.

From the eighteenth century onward, mortality patterns have been investigated through both macro and micro studies, especially in the Western world (Bengtsson 2004). These studies demonstrate gendered variations in mortality across different time-space contexts and age groups. The Tabular Commission (Tabellverket) began population statistics in 1749 (Sköld 2001), and since then we can see that the mortality among Swedish men has been higher than that among women, except for some brief time periods, and mainly among young people (Willner 1999; Fridlizius 1988; Edvinsson 1992). This male excess in mortality persisted throughout the nineteenth century although the gap between the genders decreased.

There are few historical studies on how death hit a larger number of disabled individuals and whether their mortality differed from general or gendered patterns. Our own research reveals that disability jeopardised the survival of individuals in nineteenth-century Sweden, but with some variation by type of disability and gender. Both men and women with mental disabilities and men with any type of disability ran the highest premature death risks compared to their non-disabled peers (Haage et al. 2016; Vikström et al. 2017). For East Flanders, Belgium, 17501950, De Veirman (2015) presents statistical life course results of deaf individuals. Comparing their mortality risks with those of their hearing siblings, who constitute a reference group, De Veirman cannot find that deafness significantly influenced survival chances. Olsson (1999) provides some results in her study of disabled 
people in nineteenth-century Linköping, a town in central Sweden. Measures of their longevity demonstrate that disabled women on average grew older than their male counterparts, but this did not make their mortality patterns different from the gendered death differentials outlined above.

\section{Methods}

To investigate how disabilities and the experiences of work and family during early adulthood affected subsequent mortality in past society we, have to operationalise these concepts, find adequate data and apply a suitable statistical approach to analyse the data.

The strategy chosen here is to first note the occurrence and type of disability prior to the age of 15 . Second, life trajectories are analysed using sequence analysis between ages 15 and 33 in order to determine homogeneous groups, given their experience of work and family in their early adulthood. Important demographic events that occur in the life of young adults - first occupation, first marriage and first child - are recorded yearly and cause the person's trajectory to change state. From the parish registers we know the date of the events so the dates are discretised to the age of the individual in full years. The reason for choosing young persons is that they were, in the beginning of their transition to adulthood, associated with the central events under study, getting the first job, marrying for the first time and giving birth to the first child. Third, the groups derived are used as explanatory variables in combination with disability and other variables in continuous Cox regressions with mortality as outcome. The individuals are followed from their 33rd birthday as long as the registers permit and it is noted if the period ends with death or if the observation is censored. The duration of this period is counted in days as we have dates for the events.

As indicator of different types of disabilities, notes from the parish registers are used as described in detail in the next section. As indicators of experience of work and family, we have chosen to use the occurrence of first job, first marriage and first child. These are used to create two sets of explanatory factors. Both of these are created by first looking at the yearly combination of these occurrences, giving rise to a preliminary factor variable factor with eight levels. E.g. if a person has experienced the first marriage, first child and first occupation the state will be "Married/child/occupation" for the rest of the observation period.

The first factor variable is constructed using sequence analysis by clustering them into similar groups based on similarities of the trajectories. This is done using Ward hierarchical clustering of the sequences using the optimal matching distances between the sequences of transitions between states (Studer and Ritschard 2016). The method used is implemented in TraMineR in the function seqdist as "OMstran", here used with parameters otto $=0.2$ and indel $=1$. This method is highly sensitive to the sequencing of the events which is relevant here. Substitution costs are calculated with the method "TRATE" which uses the observed transition rates. The parameter values are chosen so that they give groups that perform well in the Cox regression. 
The second factor variable we will call End-state. It is the status just before the 33rd birthday and serves as a comparison to the variable constructed above.

Two control variables indicating urban setting and cohort are also used. Cohort is defined as cohort 1 if the person is born 1820-1829 and cohort 2 if the person is born 1850-1859. The parishes are divided into rural and urban/industrial as will be detailed in the data section.

We also have access to other variables, for example indicating the socioeconomic background. We do not use it, since studies have shown this background had little effect on mortality in the period and region under study (Edvinsson and Broström 2012; Edvinsson 1992; Haage et al. 2016).

All our analyses are performed in the statistical environment $\mathrm{R}$, using the package TraMineR (Life Trajectory Miner for R, Gabadinho et al. 2011).

\section{Data}

To meet the purpose of our study, and to be able to handle the vast information about individuals and impairments reported in the DDB's parish registers, we target a young population in the Sundsvall region. The data-set consists of observations of 4,116 unique 15-year-old individuals born 1820-29 or 1850-59, of whom 74 had marks of impairments before the age of 15 years. In the following subsections, the area and parish registers that are the source of our data is described.

\subsection{Area Selected for Analysis}

The Sundsvall region is chosen as a research area. (See Fig. 1). This region is a fairly representative selection of the population makeup and the economic structure found elsewhere in nineteenth-century Sweden and north-western Europe. Also in the Sundsvall region the majority of people depended on agricultural production, especially eight parishes in this study, Attmar, Hässjö, Indal, Ljustorp, Selånger, Såttna, Tuna and Tynderö. In another four parishes, Alnö, Skön, Njurunda and Timrå, the socio-economic and demographic structure transformed from the middle of the century onwards, from agriculture to being primarily shaped by the sawmill industry. In these parishes and Sundsvall town, the effects of industrialisation were most evident. Besides the mortality decline typical for the nineteenth century, the large influx of primarily domestic migrants looking for better prospects in this expanding sawmill industry explains the rapid population growth during the latter half of the century (Bergman 2010; Edvinsson 1992; Vikström 2003). In 1840 there were 18,793 inhabitants, a number that had increased to 46,418 in 1880 (Alm Stenflo 1994). 


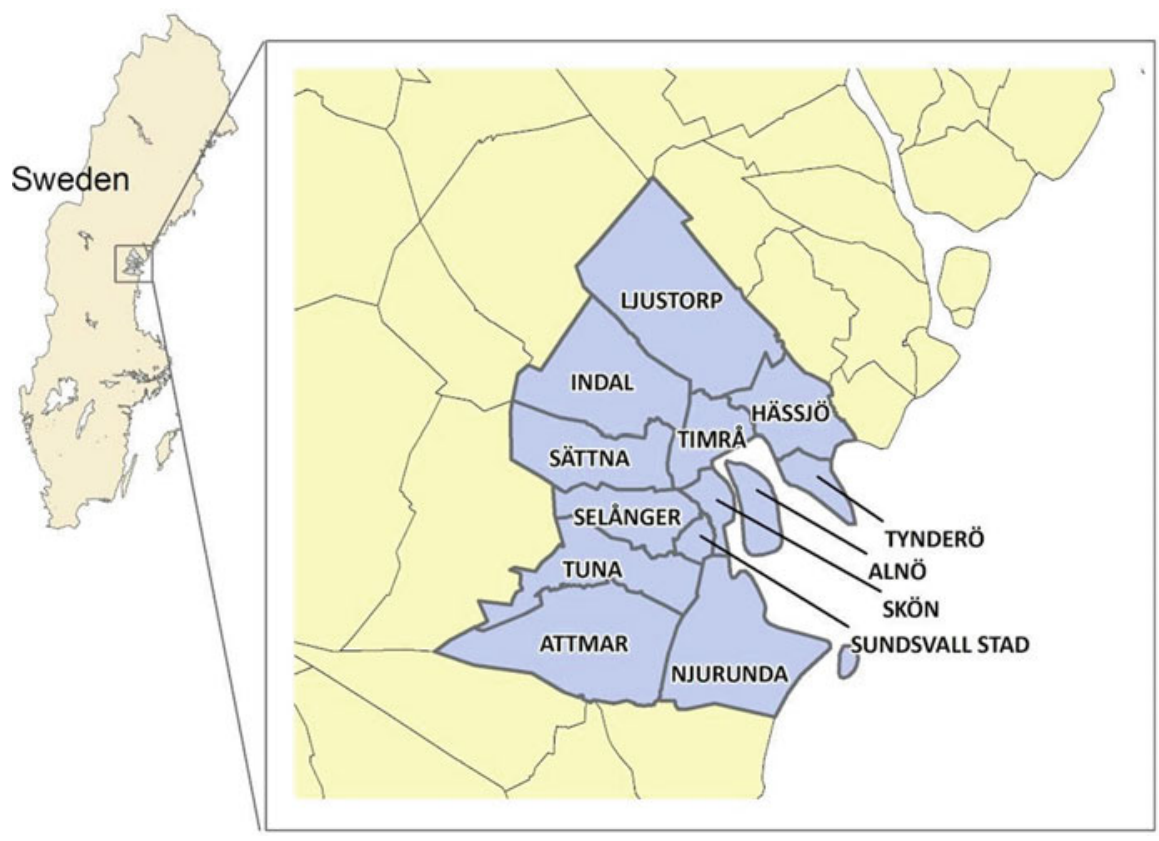

Fig. 1 Map of Sweden and the Sundsvall region and the parishes included in the study. (Source: Demographic Data Base, Umeå University)

\subsection{Digitised Parish Registers Indicating Disabilities}

The parish registers of the Sundsvall region are digitised and stored by the Demographic Data Base (DDB) at Umeå University, Sweden. They are based on original registers for parishioners' birth, baptism, marriage, outward or inward migration, death and burial and the catechetical examination records. They also provide notes on occupation. As all these registers are digitised and linked on an individual level, they yield a demographic description of each parishioner containing essential life events, such as the start and type of work, marriage, childbearing, relocation or death (Westberg et al. 2016; Vikström et al. 2006). The rich information across an individual's lifetime makes the DDB registers well suited for life course research.

The catechetical examination records (husförhörslängder) explain why Sweden's parish registers are exceptionally informative. They go back to the seventeenth century, due to the obligation of the church ministers to keep records of the parishioners' knowledge of the catechism and their reading skills (Nilsdotter Jeub 1993). In these records, the ministers reported events such as occupational changes and also made other notes about the parishioners, such as remarks about their impairments (lytesmarkeringar), which indicate the presence of disabilities. Parishioners whom the ministers recognised as disabled have been manually categorised as such by us, since this information is not consistently coded by the DDB. Further, we account 
Table 1 The categorisation of disability based on the notes of impairment in the parish registers from the Sundsvall region, 1835-1844 and $1865-1874$

\begin{tabular}{l|l}
\hline Disability & Description \\
\hline Blind & $\begin{array}{l}\text { Visual defects from weak-sighted, } \\
\text { short-sighted to blind }\end{array}$ \\
\hline Deaf mute & $\begin{array}{l}\text { Hearing or communication dysfunctions, } \\
\text { ranging from poor hearing to deaf and } \\
\text { from difficulties speaking, stammer to } \\
\text { mute }\end{array}$ \\
\hline Crippled & $\begin{array}{l}\text { Physical dysfunctions e.g. lame, limping, } \\
\text { walking on crutches, missing body parts, } \\
\text { hare-lipped, small in size or crippled }\end{array}$ \\
\hline Idiot & $\begin{array}{l}\text { Mental dysfunctions since childhood and } \\
\text { lack of full intellectual development as an } \\
\text { adult, e.g. foolish, silly or less cognisant } \\
\text { (Mindre vetande) }\end{array}$ \\
\hline Insane & $\begin{array}{l}\text { Mental dysfunctions identified in } \\
\text { adulthood and fully developed intellect as } \\
\text { a child, e.g. insane, feeble-minded or } \\
\text { crazy }\end{array}$ \\
\hline Multiple disabilities & $\begin{array}{l}\text { Combination of two or more of the above } \\
\text { disabilities }\end{array}$ \\
\hline
\end{tabular}

only for fairly evident impairments, such as hearing and visual disabilities and a few other types of physical or mental dysfunctions described in Table 1 . In the analysis we have merged the two groups that ministers labelled as idiots or insane into a new group that we term "mentally disabled". All other disability groups are merged into one group called "other disabilities" in the Cox regression. This facilitates comparisons both within the group of disabled people and with parishioners in the Sundsvall region who did not have any of these particular impairments reported in the parish registers. Thus, those who were not blind, deaf mute or crippled and so forth we recognise as being non-disabled, even though some of them may have had impairments more vaguely defined by the ministers or perhaps suffered from some illnesses (Drugge 1988; Haage et al. 2017; Rogers and Nelson 2003). They represent the average, or typical, life trajectory of the population living in the same time-space context as did the group of disabled people.

Of course, there is a risk of underestimating disabilities in the parish registers, as this type of documentation was not the primary task of the ministers. However, this is not a big problem, as disabled persons who may have been incorrectly added to the group of non-disabled people will affect the results very little and because we can be fairly certain that those in the group with disabilities were in fact disabled.

In Table 2 the frequencies and mean observation time for the different disability groups are presented. Observation time is the time in years from observation start at the 33 birthday until death or censoring. There are considerable differences between the groups in follow up time due to different mortality and migration patterns.

In Table 3 the frequencies and mean observation time for the different end types are shown. Of all observations, 919 end with death, the outcome we are interested in. 
Table 2 Frequency and mean observation time in years after the 15 th birthday by disability group

\begin{tabular}{l|c|l}
\hline Disability & Frequency & Mean observation time \\
\hline Non-disabled & 4042 & 16.00 \\
\hline Blind & 6 & 32.11 \\
\hline Crippled & 14 & 20.04 \\
\hline Deaf mute & 22 & 17.48 \\
\hline Mentally disabled & 32 & 14.02 \\
\hline
\end{tabular}

Table 3 Frequency and mean observation time in years by end type

\begin{tabular}{l|c|c}
\hline End & Frequency & Mean observation time \\
\hline Unknown & 14 & 7.56 \\
\hline Registers end & 2545 & 16.15 \\
\hline Dead & 919 & 21.91 \\
\hline Migrated & 638 & 7.26 \\
\hline
\end{tabular}

\section{Results}

First, results from the sequence analysis are presented, followed by the KaplanMeier curves for survival for the different groups derived in the sequence analysis. Lastly, the results of the Cox regressions are presented.

\subsection{Sequence Analysis Results}

In Fig. 2 the transversal state distribution within each cluster found in the cluster analysis for men is shown. Three typical types are found. Type 1 gets a job but does not get a family quickly. Type 2 gets a job, gets married and has a child rather quickly. Type 3 is characterised by not getting a job or family until late in the observation period or not at all.

The pattern for women shown in Fig. 3 is a bit different. Type 1 starts a family but does not get a job. Type 2 gets a job early and then most get a family. The third type is, as for the men, characterised by not getting a job or family until late in the period or not at all.

These identified types below are used as stratification variables to make KaplanMeier curves and in the Cox regression as explanatory variables to see if they affect mortality.

\subsection{Kaplan-Meier Curves}

The $\mathrm{x}$-axis in the Kaplan-Meier curve is years after the 33rd birthday. $p$-values in the caption of the figures refer to log-rank or Mantel-Haenszel tests (Harrington and Fleming 1982). 
Type 1

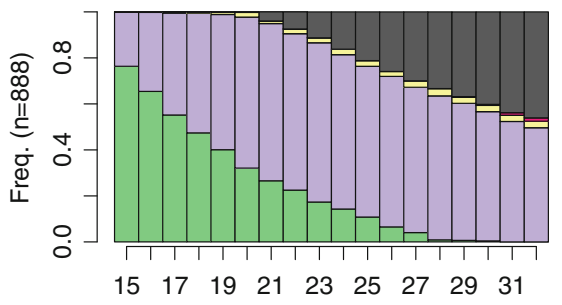

Type 3

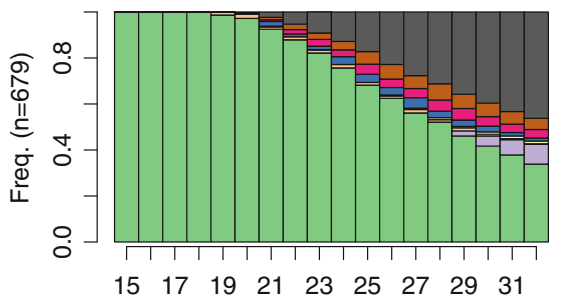

Type 2

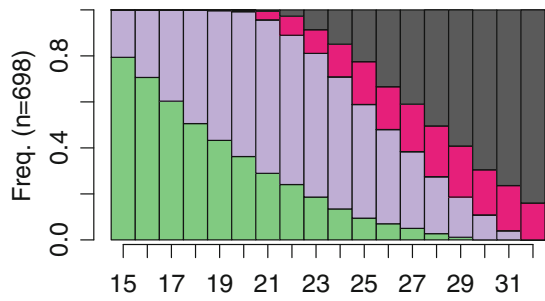

$\square$ Unmarried/No child/No occupation

$\square$ Unmarried/No child/Occupation

$\square$ Unmarried/Child/No occupation

$\square$ Unmarried/Child/Occupation

$\square$ Married/No child/No occupation

$\square$ Married/No child/Occupation

$\square$ Married/Child/No occupation

$\square$ Married/Child/Occupation

Fig. 2 Transversal state distributions for the types found for men

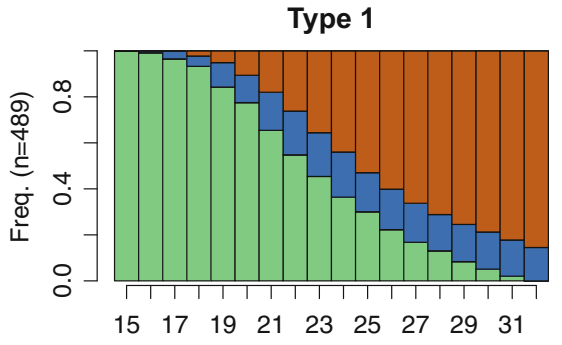

Type 3

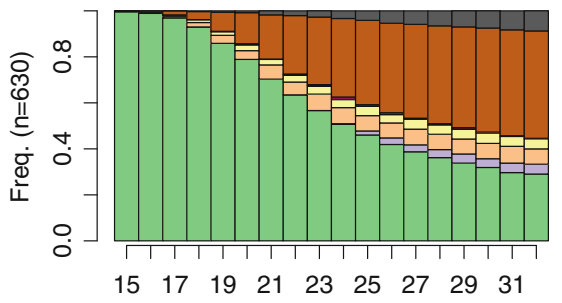

Type 2

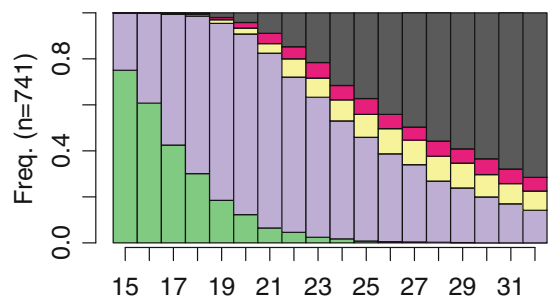

$\square$ Unmarried/No child/No occupation

$\square$ Unmarried/No child/Occupation

$\square$ Unmarried/Child/No occupation

$\square$ Unmarried/Child/Occupation

$\square$ Married/No child/No occupation

$\square$ Married/No child/Occupation

$\square$ Married/Child/No occupation

$\square$ Married/Child/Occupation

Fig. 3 Transversal state distributions for the types found for women 


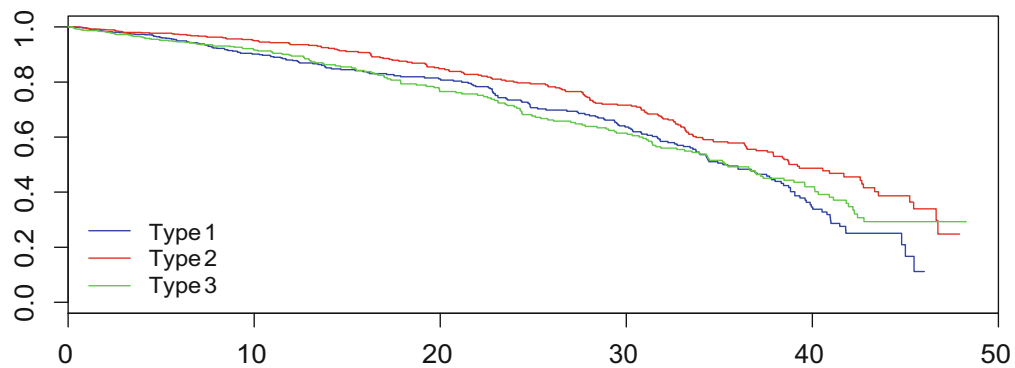

Fig. 4 Kaplan-Meier by type according to sequence analysis, men, $p$-value: 0.001

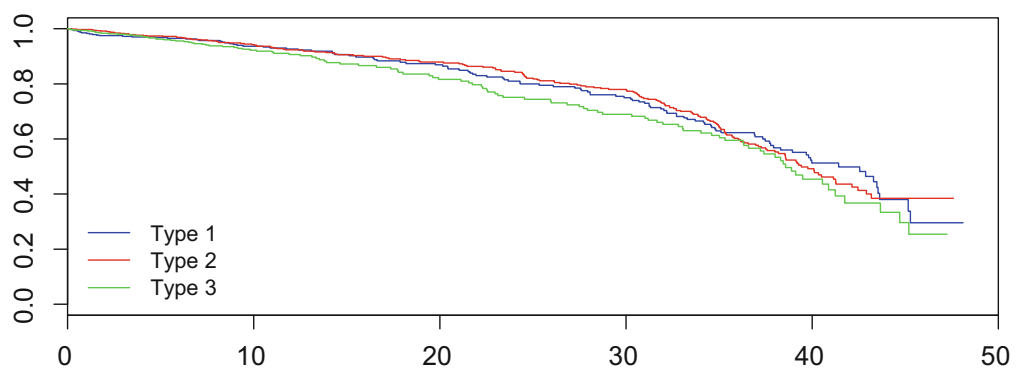

Fig. 5 Kaplan-Meier by type according to sequence analysis, women, $p$-value: 0.235

Figures 4 and 5 show the Kaplan-Meier curves for the types extracted for men and women respectively in the sequence analysis. The curves for men are significantly different with a lower mortality for type 2, those that achieved both work and family. The curves for women are not significantly different but there is a tendency for type 3, those that remained without family and work longest, to have a slightly lower curve indicating higher mortality.

\subsection{Cox Regression Results}

Four different models are analysed with Cox regression, two for men and two for women. The genders are analysed in different models as it is likely that mortality patterns differ. Within gender the models differ depending whether Endstate or Type is used as explanatory variables. Reference level for End-state is married/child/occupation and for Types, Type 1. Variables controlling for urban or rural setting (Rural/Urban) and cohort inclusion (Cohort) are also used. Reference levels for these variables are Rural and Cohort 1. Proportionality tests for all models indicate no significant violations of the proportionality assumption.

The results are shown in Table 4. The significance test for the complete factor variables (Disability, End-status, Type, Urban and Cohort) as shown in Table 5 
Table 4 Cox regression estimates as hazard ratios. Reference levels are Non-disabled, Married/child/occupation, Men Type 1, Women Type 1, Rural parish and Cohort 1

\begin{tabular}{l|l|l|l|l}
\hline \multirow{2}{*}{} & \multicolumn{4}{l}{ Hazard ratios for mortality } \\
\cline { 2 - 5 } & Men & Women & Men & Women \\
\cline { 2 - 5 } & $(1)$ & $(2)$ & $(3)$ & $(4)$ \\
\hline Mentally disabled & 1.516 & $3.620^{* *}$ & 1.446 & $3.512^{* *}$ \\
\hline Other disability & 1.064 & 0.903 & 1.036 & 0.883 \\
\hline Unmarried/No child/No occupation & 1.097 & 1.115 & & \\
\hline Unmarried/No child/Occupation & $1.273^{* *}$ & 1.097 & & \\
\hline Unmarried/Child/No occupation & 0.0004 & 1.167 & & \\
\hline Unmarried/Child/Occupation & 1.572 & 1.001 & & \\
\hline Married/No child/No occupation & 0.596 & 0.905 & & \\
\hline Married/No child/Occupation & 1.113 & 0.882 & & \\
\hline Married/Child/No occupation & 1.017 & 1.022 & & \\
\hline MenType 2 & & & $0.689 * * *$ & \\
\hline MenType 3 & & & 0.916 & \\
\hline WomenType 2 & & & & 1.022 \\
\hline WomenType 3 & & & & 1.203 \\
\hline Urban/Industrial & 1.113 & 1.151 & 1.112 & 1.147 \\
\hline Cohort 2 & 1.029 & 0.813 & 1.004 & 0.796 \\
\hline Observations & 2,262 & 1,854 & 2,262 & 1,854 \\
\hline
\end{tabular}

${ }^{*} p<0.1 ;{ }^{* *} p<0.05 ;{ }^{* * *} p<0.01$

Table $5 p$-values for the factors in the four models

\begin{tabular}{l|l|l|l|l}
\hline Model & $(1)$ & $(2)$ & $(3)$ & $(4)$ \\
\hline Factor: & & & & \\
\hline Disability & 0.59 & 0.11 & 0.66 & 0.12 \\
\hline Cohort & 0.85 & 0.26 & 0.98 & 0.22 \\
\hline End-status & 0.49 & 0.99 & & \\
\hline Type Men & & & 0.00 & \\
\hline Type Women & & & & 0.35 \\
\hline Rural/Urban & 0.29 & 0.24 & 0.29 & 0.25 \\
\hline
\end{tabular}

shows a significant result at the 5\% significance level only for the type of men variable derived from the sequence analysis. However, comparing levels within factor, mentally disabled women have a significantly higher mortality than nondisabled women in Model 2 and 4. For men, having a job, wife and family, implied significantly lower mortality risk than if only having a job in Model 1.

\section{Discussion}

This study combines sequence analysis with event history analysis to examine how past trajectories in terms of work and family determined mortality among disabled and non- disabled individuals in nineteenth-century Sweden. We find that sequence 
analysis is a useful tool to encapsulate information from people's life histories and then make use of this information in Cox regressions to gain evidence on how past trajectories shaped subsequent events in life, here mortality. While the results from using end states did not render any significant outcome, two major findings stand out from our examination of the variables constructed by sequence analysis. First, it seems as if experiencing work and family during young adult life (between 15 and 33 years of age) significantly affected subsequent mortality, but only for men. The trajectories that consist of job, marriage and children, often perceived as the desirable life path, seem beneficial for men. This suggests that men's survival was more sensitive to having a job, a spouse and family than was the case for women. Our second major finding regards the effect of disability, or rather the low impact of it. While mental disabilities among women made them run significantly higher mortality risks, such an effect was insignificant among women having other types of disabilities. The effect of disability was also insignificant among and all men. However, it is possible that some of the negative effect of disability is captured in the variables based on past trajectories. There may be yet another reason contributing to the absence of significant effects of disability on mortality and it concerns a possible selection bias. It must be borne in mind that all individuals under observation have survived their 33rd birthday. This implies that the persons most frail in the disability group, which we expect to be more vulnerable than the non-disabled group, have already died before reaching this age, probably leaving the strongest and healthiest disabled persons for us to study. Moreover, according to the "healthy migrant theory" (Abraido-Lanza et al. 1999), frail people tend to relocate to a low extent, just as did the disabled individuals we analyse in comparison to the high level of migrants in the non- disabled group. If frail people from the latter group did not move and thus are included in our follow up, this partly explains the low mortality difference between the two groups. However, the life-course results we obtain through a combination of sequence analysis and event history analysis suggest that disability cannot only be associated with the disadvantages indicated above with high mortality risks. Obviously, getting a job, spouse and family during young adulthood helped to limit nineteenth-century individuals' death risks later in life even if disability was part of it.

Acknowledgements This study is part of a project headed by Lotta Vikström that has received funding from the European Research Council (ERC) under the European Union's Horizon 2020 research and innovation programme (Grant Agreement No. 647125), 'DISLIFE Liveable Disabilities: Life Courses and Opportunity Structures Across Time'. The study is also part of another project led by Lotta Vikström, 'Experiences of disabilities in life and online: Life course perspectives on disabled people from past society to present', funded by the Wallenberg Foundation (Stiftelsen Marcus och Amalia Wallenbergs Minnesfond). The authors wish to thank the three anonymous reviewers and the editors for providing suggestions on how to advance our analysis. We are also grateful to all the support regarding both research and data that we enjoy from our colleagues at the Centre for Demographic and Ageing Research (CEDAR) and the Demographic Data Base (DDB), Umeå University, Sweden. 


\section{References}

Abraido-Lanza, A. F., Dohrenwend, B. P., Ng-Mak, D. S., Turner, J. B. (1999). The Latino mortality paradox: A test of the "salmon bias" and healthy migrant hypotheses. American Journal of Public Health, 89(10), 1543-1548.

Alm Stenflo, G. (1994). Demographic description of the Skelleftea and Sundsvall regions during the 19th century. Umeå: Demographic Data Base.

Bengtsson, T. (2004). Living standards and economic stress. Life under pressure: Mortality and living standards in Europe and Asia, 1700-1900 (pp. 27-59). Cambridge: The MIT Press.

Bergman, M. (2010). Constructing communities: The establishment and demographic development of sawmill communities in the Sundsvall district, 1850-1890. Technical report, Umeå: Umeå University.

Bras, H., Liefbroer, A. C., Elzinga, C. H. (2010). Standardization of pathways to adulthood? An analysis of Dutch cohorts born between 1850 and 1900. Demography, 47(4), 1013-1034.

Courgeau, D. (2018). Do different approaches in population science lead to divergent or convergent models. In G. Ritschard \& M. Studer (Eds.), Sequence analysis and related approaches: Innovative methods and applications. Cham: Springer (this volume).

De Veirman, S. (2015). Breaking the silence: The experiences of deaf people in East Flanders, 1750-1950: A life course approach. Ph.D. thesis, Ghent University.

Dribe, M., Manfredini, M., Oris, M. (2014). The roads to reproduction: Comparing life-course trajectories in Preindustrial Eurasia. In C. Lundh, Kurosu, S., et al. (Ed.), Similarity in difference: Marriage in Europe and Asia, 1700-1900. Cambridge, MA: MIT Press.

Drugge, U. (1988). Om husförhörslängder som medicinsk urkund. Psykisk sjukdom och förståndshandikapp i en historisk källa. Scriptum. Rapportserie utgiven av forskningsarkivet vid Umeå universitet, 8.

Edvinsson, S. (1992). Den osunda staden: Sociala skillnader i dödlighet i 1800-talets Sundsvall. Ph.D. thesis, Umeå universitet.

Edvinsson, S., \& Broström, G. (2012). Old age, health and social inequality: Exploring the social patterns of mortality in 19th-century Northern Sweden. Demographic Research, 26, 633-660.

Eerola, M. (2018). Case studies of combining sequence analysis and modelling. In G. Ritschard \& M. Studer (Eds.), Sequence analysis and related approaches: Innovative methods and applications. Cham: Springer (this volume).

Fridlizius, G. (1988). Sex-differential mortality and socio-economic change: Sweden 1750-1910. In A. Brändström \& L.-G. Tedebrand (Eds.), Society, health and population during the demographic transition (pp. 237-272). Stockholm: Almqvist \& Wiksell International.

Gabadinho, A., Ritschard, G., Müller, N. S., Studer, M. (2011). Analyzing and visualizing state sequences in R with TraMineR. Journal of Statistical Software, 40(4), 1-37.

Haage, H., Häggström Lundevaller, E., Vikström, L. (2016). Gendered death risks among disabled individuals in Sweden: A case study of the 19th-century Sundsvall region. Scandinavian Journal of History, 41(2), 160-84.

Haage, H., Vikström, L., Häggström Lundevaller, E. (2017). Disabled and unmarried? Marital chances among disabled people in nineteenth-century Northern Sweden. Essays in Economic \& Business History, 35(1), 207-238.

Harrington, D. P., \& Fleming, T. R. (1982). A class of rank test procedures for censored survival data. Biometrika, 69, 553-566.

Kok, J. (2007). Principles and prospects of the life course paradigm. Annales de démographie historique (1), 203-230.

Madero-Cabib, I., Gauthier, J.-A., Le Goff, J.-M. (2015). The influence of interlocked employment-family trajectories on retirement timing. Work, Aging and Retirement, 2(1), 3853.

Nilsdotter Jeub, U. (1993). Parish records: 19th century ecclesiastical registers. Umeå, Umeå University: Information from the Demographic Data Base. 
Olsson, I. (1999). Att leva som lytt: Handikappades levnadsvillkor i 1800-talets Linköping. Ph.D. thesis, Tema, Linköpings universitet.

Oris, M., \& Ritschard, G. (2014). Sequence analysis and transition to adulthood: An exploration of the access to reproduction in nineteenth-century East Belgium. In Advances in sequence analysis: Theory, method, applications(pp. 151-167). Springer, Cham.

Ritschard, G., Gabadinho, A., Muller, N. S., Studer, M. (2008). Mining event histories: A social science perspective. International Journal of Data Mining, Modelling and Management, 1(1), 68-90.

Ritschard, G., \& Oris, M. (2005). Life course data in demography and social sciences: Statistical and data-mining approaches. Advances in Life Course Research, 10, 283-314.

Rogers, J., \& Nelson, M. C. (2003). "lapps, Finns, Gypsies, Jews and Idiots" modernity and the use of statistical categories in Sweden. Annales de démographie historique, 1(105), 61-79.

Rossignon, F., Studer, M., Gauthier, J.-A., Le Goff, J.-M. (2018). Sequence history analysis (SHA): Estimating the effect of past trajectories on an upcoming event. In G. Ritschard \& M. Studer (Eds.), Sequence analysis and related approaches: Innovative methods and applications. Cham: Springer (this volume).

Schumacher, R., Matthijs, K., \& Moreels, S. (2013). Migration and reproduction in an urbanizing context. Family life courses in 19th-century Antwerp and Geneva. Revue Quetelet, 1, 51-72.

Sköld, P. (2001). Kunskap och kontroll: Den svenska befolkningsstatistikens historia. Almqvist \& Wiksell.

Studer, M., \& Ritschard, G. (2016). What matters in differences between life trajectories: A comparative review of sequence dissimilarity measures. Journal of the Royal Statistical Society: Series A (Statistics in Society), 179(2), 481-511.

Vikström, L. (2003). Gendered routes and courses: The socio-spatial mobility of migrants to nineteenth-century Sundsvall. Umeå: Umeå University, Demographic Data Base.

Vikström, L., Haage, H., Häggström Lundevaller, E. (2017). Sequence analysis of how disability influenced life trajectories in a past population from the nineteenth-century Sundsvall region, Sweden. Historical Life Course Studies, 4, 97-119.

Vikström, P., Brändström, A., Edvinsson, S. (2006). Longitudinal databases: Sources for analyzing the life course. History and Computing, 14, 109-128.

Westberg, A., Engberg, E., Edvinsson, S. (2016). A unique source for innovative longitudinal research: The POPLINK database, historical life course studies. Vol. 3, 20-31.

Willner, S. (1999). Det svaga könet?: Kön och vuxendödlighet i 1800-talets Sverige. Ph.D. thesis, Linköpings Universitet.

Open Access This chapter is licensed under the terms of the Creative Commons Attribution 4.0 International License (http://creativecommons.org/licenses/by/4.0/), which permits use, sharing, adaptation, distribution and reproduction in any medium or format, as long as you give appropriate credit to the original author(s) and the source, provide a link to the Creative Commons license and indicate if changes were made.

The images or other third party material in this chapter are included in the chapter's Creative Commons license, unless indicated otherwise in a credit line to the material. If material is not included in the chapter's Creative Commons license and your intended use is not permitted by statutory regulation or exceeds the permitted use, you will need to obtain permission directly from the copyright holder. 